\title{
CORN COB POLYMER FLOCCULANT PREPARATION METHOD AND ITS APPLICATION IN ORGANIC WASTE WATER TREATMENT
}

\author{
Ze Li, Wanhai, Li* \\ School of Resources and Environmental Engineering, Jilin Institute of Chemical Technology, Jilin 132022, China. \\ *Corresponding Author Email: 2532272507@qq.com
}

This is an open access article distributed under the Creative Commons Attribution License, which permits unrestricted use, distribution, and reproduction in any medium, provided the original work is properly cited

\section{ARTICLE DETAILS}

\section{Article History:}

Received 26 June 2018 Accepted 2 july 2018 Available online 1 August 2018

\section{ABSTRACT}

\begin{abstract}
In this paper, the corn cob was modified to prepare cellulose xanthogen with flocculation. A comparative experiment was conducted on the flocculating adsorption effect of the finished product. Experiments show the best experimental conditions during the modification of the corn cob. It is known from the literature that the adsorption and flocculation of heavy metal ions is better. This article focuses on the effect of the finished product on the removal of $\mathrm{Cu}^{2+}$ in coppercontaining wastewater. It was found that under certain conditions, cellulose xanthogen prepared from corn cobs can remove $\mathrm{Cu}^{2+}$ from wastewater. The rate can reach more than $90 \%$.
\end{abstract}

\section{KEYWORDS}

Cellulose xanthogen, Corn cob, Flocculant

\section{INTRODUCTION}

In this paper, corncobs with high yields have been chemically modified to obtain natural polymer flocculants. The modified natural polymer flocculants have a wide range of molecular weight distribution, many active groups and a variety of structures, and their raw materials. The source is abundant, the price is low, especially outstanding is it is safe and nontoxic, can be completely biodegradable, has good environmental acceptability [1-3]. As a kind of agricultural waste, corn cobs have been used as farm fuels for the most part. In recent years, with the continuous advancement of science and technology in China, the field of deep processing of corn cobs has been expanding, and a series of high valueadded products such as furfural, xylose, xylitol, and xylo-oligosaccharides have successively achieved industrialized production. The corn cob resources have been obtained. Make full use of [4]. In this paper, a twostep modification of corn cob, including swelling and grafting reaction, was used to prepare a crude flocculant with cellulose xanthogen as the main component.

\section{MATERIALS AND METHODS}

\subsection{Experimental raw materials}

\subsubsection{Natural corn cob}

The dried corn cobs are first crushed into coarse granules by conventional mechanical methods, dried in an oven, and then crushed into powder by a pulverizer and collected through a 80-mesh sieve for use.

\subsection{Experimental instruments and reagents}

Centrifuge, Magnetic electric mixer, Spectrophotometer, Analytical Balances, Filtering device, Distillation device, Universal Crusher, Electric blast drying box. Carbon disulfide, Magnesium sulfate, Anhydrous ethanol, Copper sulfate pentahydrate, Sodium hydroxide, Chloroform, Ammonium hydroxide, Diethyldiamine sodium dithiocarbamate.

\subsection{Experimental method}

\subsubsection{Preparation of corn cob xanthic acid}

The crushed and dried corncob powder is immersed and swelled in
$10 \% \sim 20 \% \mathrm{NaOH}$ solution for $15 \sim 30 \mathrm{~h}$, filtered and dried to obtain alkali cellulose; $\mathrm{CS}_{2}$ reaction is added to the solution; and the soluble magnesium salt is used for the transition reaction to the solution. Diluted magnesium salt and alcohol were added, suction filtered, pressed dry, and dried to obtain the corn cob xanthate.

\subsubsection{Method for treating copper-containing wastewater by corn cob} xanthate

Take a certain concentration of $\mathrm{Cu}^{2+}$-containing wastewater, adjust the $\mathrm{pH}$ value of the wastewater, add the corn cob xanthate to the wastewater, stir, filter, and effluent, and determine the $\mathrm{Cu}^{2+}$ ion content in the water by spectrophotometry.

\section{EXPERIMENTAL RESULTS AND DISCUSSION}

\subsection{Drawing of standard curve}

\subsubsection{Standard curve drawing test}

The sample was dissolved with dilute sulfuric acid and the $\mathrm{pH}$ was adjusted to 9. A stable yellow complex was formed between the copper reagent and copper ions. The mixture was extracted with chloroform and the absorbance was measured at a wavelength of $430 \mathrm{~nm}$ at the spectrophotometer. Specific steps are as follows: Place the sample in a $300 \mathrm{ml}$ beaker and add $20 \mathrm{ml}$ of sulphuric acid solution. Heat the sample at a low temperature to dissolve completely, cool, transfer to a $50 \mathrm{ml}$ volumetric flask, dilute to the mark with water, and mix. Pipette $25 \mathrm{ml}$ of the solution in a 125-ml separatory funnel. Add $25 \mathrm{ml}$ citric acid solution. Neutralize with ammonium hydroxide to a solution $\mathrm{pH}$ of about $9.10 \mathrm{ml}$ of copper reagent solution was added, $20 \mathrm{ml}$ of chloroform was added, shaken for $2 \mathrm{~min}$, allowed to stand for stratification, and the aqueous phase was discarded. The organic phase was transferred to a $1 \mathrm{~cm}$ cuvette and trichloromethane was used as a reference to measure the absorbance at a wavelength of $430 \mathrm{~nm}$ at the spectrophotometer. Subtract the absorbance of the blank test performed with the sample.

\subsection{Selection of preparation conditions for corn cob xanthate}

3.2.1 Effect of Alkaline Concentration on the Properties of Corncob Xanthate 
Take 3g corncob powder, use $10 \%, 15 \%, 20 \%$ and $25 \% \mathrm{NaOH}$ solution, alkalinize at $20^{\circ} \mathrm{C}$, add $1.5 \mathrm{ml} \mathrm{CS}$, and yellow at $30^{\circ} \mathrm{C}$ for $2 \mathrm{~h}$. The $\mathrm{Cu}^{2+}$ ion wastewater with an initial concentration of $10.0 \mathrm{mg} / \mathrm{l}$ was treated with the synthetic corn cob xanthate, stirred for $30 \mathrm{~min}$, and the measured copper ion concentration was determined as shown in Table 1.

Table 1: The Influence of Different Alkali Concentration on Flocculation Properties

\begin{tabular}{|llllc|}
\hline Alkali concentration & $10 \%$ & $15 \%$ & $20 \%$ & $25 \%$ \\
\hline Absorbance & 0.91 & 0.86 & 0.73 & 0.83 \\
$\mathrm{Cu}^{2+}$ concentration & 0.72 & 0.68 & 0.58 & 0.66 \\
Removal rate & $92.8 \%$ & $93.2 \%$ & $94.2 \%$ & $93.4 \%$ \\
\hline
\end{tabular}

Since the alkali concentration affects the cellulose purity after the swelling of the corn cob, and then affects the nature of the corn cob xanthic acid, resulting in different flocculation performance, from the above data, we can see that the best flocculation is achieved when the alkali concentration is $20 \%$. effect.

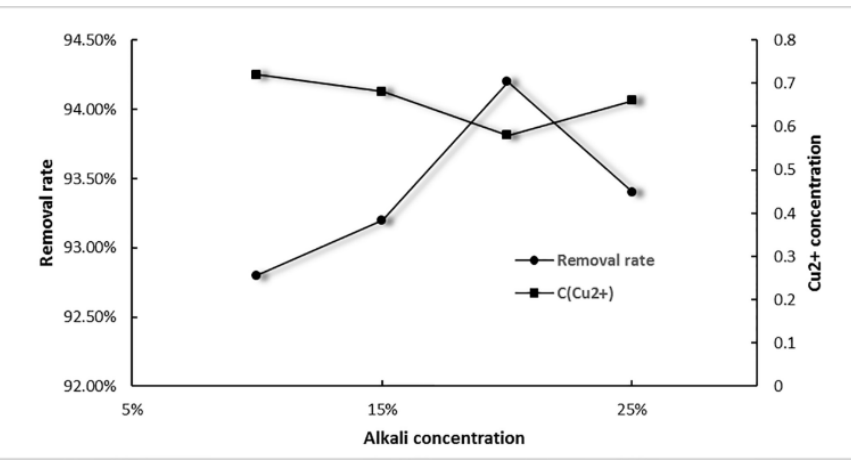

Figure 1: The Influence of Different Alkali Concentration on Flocculation Properties

\subsubsection{Effect of Alkaline Temperature on the Performance of Wood Xanthate}

Take 3g corncob powder, the alkali concentration of $20 \%, \mathrm{CS}_{2}$ dosage of $1.0 \mathrm{ml}$, yellowing reaction temperature $30^{\circ} \mathrm{C}$, When the yellowing reaction time is $2 \mathrm{~h}$, the alkalizing temperature is $20^{\circ} \mathrm{C}, 40^{\circ} \mathrm{C}, 60^{\circ} \mathrm{C}$, and $80^{\circ} \mathrm{C}$, respectively. Synthetic corn cob Xanthate is treated with $\mathrm{Cu}^{2+}$ solution with an initial concentration of $10 \mathrm{mg} / \mathrm{l}$, The copper ion concentration after the reaction was measured is shown in Table 2.

Table 2: The Influence of Different Swelling Temperature on Flocculation Properties

\begin{tabular}{|lcccc|}
\hline Swelling temperature ${ }^{\circ} \mathrm{C}$ & 20 & 40 & 60 & 80 \\
\hline Absorbance & 0.86 & 0.88 & 1.19 & 1.38 \\
$\mathrm{Cu}^{2+}$ concentration & 0.68 & 0.70 & 0.95 & 1.13 \\
Removal rate & $93.2 \%$ & $93.0 \%$ & $90.5 \%$ & $88.7 \%$ \\
\hline
\end{tabular}

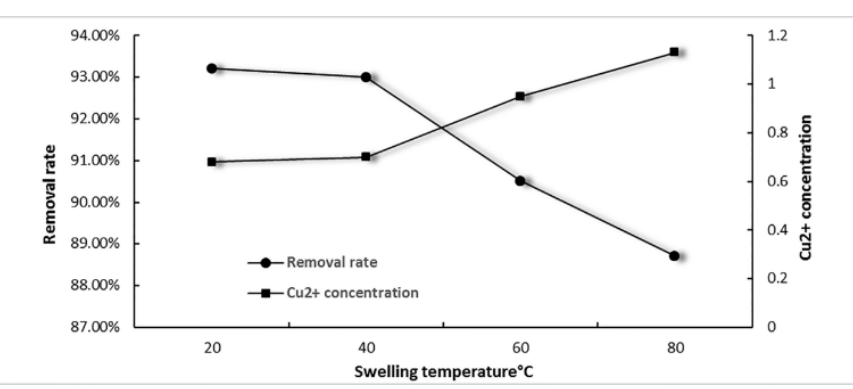

Figure 2: The Influence of Different Swelling Temperature on Flocculation Properties

In the process of swelling, the alkalinization temperature is also a very important condition. From the above data, it can be seen that the xanthic acid obtained from the alkalization at $20^{\circ} \mathrm{C}$. has the best adsorption flocculating performance.

\subsubsection{Effect of carbon disulfide dosage on the performance of corn cob xanthate}

Take 3g corncob powder and soak at $20^{\circ} \mathrm{C}$ for $24 \mathrm{~h}$ under $20 \%$ alkali concentration to obtain alkali cellulose. The amount of $\mathrm{CS}_{2}$ used for yellowing was taken as follows: $0.1667,0.3333,0.5000,0.6667 \mathrm{ml} / \mathrm{g}$, and yellowing at $30^{\circ} \mathrm{C}$ for $2.0 \mathrm{~h}$. The prepared corn cob xanthate is treated with a copper ion solution having an initial concentration of $10.0 \mathrm{mg} / \mathrm{l}$. The copper ion concentration after the reaction was measured is shown in Table 3. From the above data, it can be seen that cornstard xanthogen has the best flocculation effect when $\mathrm{CS}_{2}$ dosage is $0.5 \mathrm{ml} / \mathrm{g}$.

Table 3: The Influence of Different $\mathrm{CS}_{2}$ Dosage on Flocculation Properties

\begin{tabular}{|llccc|}
\hline $\mathrm{CS}_{2}$ amount $(\mathrm{ml} / \mathrm{g})$ & 0.1667 & 0.3333 & 0.5000 & 0.6667 \\
\hline Absorbance & 0.72 & 0.51 & 0.41 & 0.56 \\
$\mathrm{Cu}^{2+}$ concentration & 0.56 & 0.39 & 0.31 & 0.43 \\
Removal rate & $94.4 \%$ & $96.1 \%$ & $96.9 \%$ & $95.7 \%$ \\
\hline
\end{tabular}

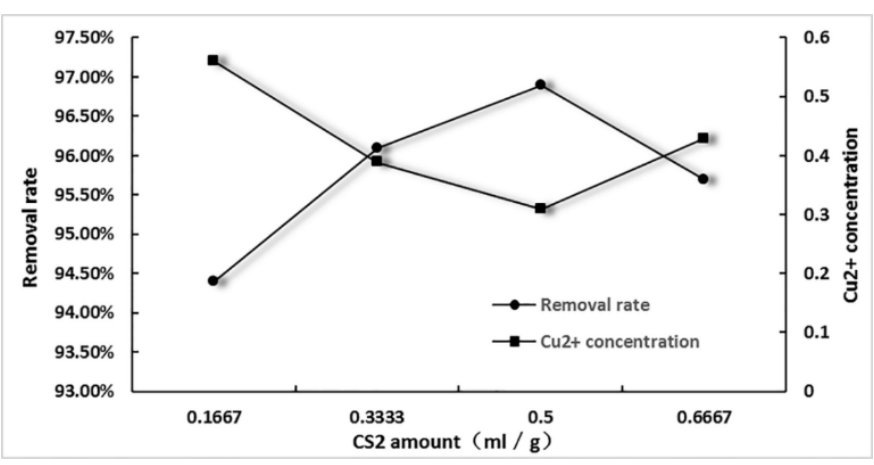

Figure 3: The Influence of Different $\mathrm{CS}_{2}$ Dosage on Flocculation Properties

\subsection{Application of Corncob Xanthate Modified Flocculant in Wastewater}

\subsubsection{Effect of corn cob xanthate dosage on the treatment of heavy metal wastewater}

The $\mathrm{Cu}^{2+}$ ion simulation wastewater concentration is $10 \mathrm{mg} / \mathrm{l}$, the $\mathrm{pH}$ is 7 and the simulation wastewater is $100 \mathrm{ml}$ each time. Add corncob xanthates $0.1,0.3,0.5,0.7$, and $0.9 \mathrm{mg} / \mathrm{g}$, respectively, and stir at room temperature for $30 \mathrm{~min}$. The filtrate was taken for ion concentration detection. The results obtained are shown in Table 4.

Table 4: The Influence of Different Product Dosageon Flocculation Properties

\begin{tabular}{|llcccc|}
\hline Finished product $(\mathrm{mg} / \mathrm{g})$ & 0.1 & 0.3 & 0.5 & & 0.9 \\
\hline Absorbance & 1.69 & & 0.87 & 0.56 & 0.60 \\
$\mathrm{Cu}^{2+}$ concentration & 1.56 & 1.39 & & & 0.47 \\
Removal rate & $84.4 \%$ & $86.1 \%$ & $92.9 \%$ & $95.7 \%$ & $95.3 \%$ \\
\hline
\end{tabular}

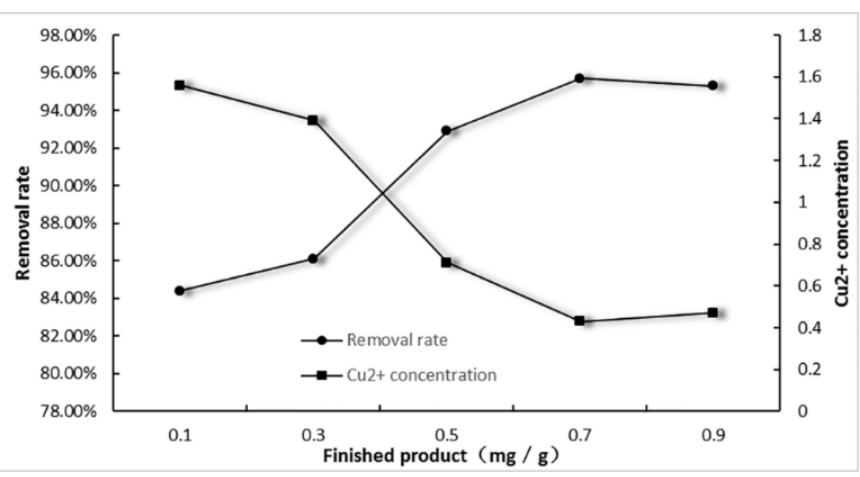

Figure 4: The Influence of Different Product Dosage on Flocculation Properties

From the above icons, it can be seen that when the dosage of finished flocculant is about $0.7 \mathrm{mg} / \mathrm{g}$, there is better flocculation performance.

\subsubsection{Effect of pH Value of Heavy Metal Waste Water on Treatment Effect}

Take a certain concentration of copper ion wastewater $100 \mathrm{ml}$, the $\mathrm{pH}$ adjusted with $25 \%$ sodium hydroxide and $10 \%$ sulfuric acid were: $3,5,7$, 9,10 , respectively. Add corn cob xanthate at $1 \mathrm{mg} / \mathrm{g}$, and stir at room temperature for $30 \mathrm{~min}$. Take the filtrate for ion detection. The results are shown in Table 5: 
Table 5: The Influence of Different pH Value on Flocculation Properties

\begin{tabular}{|lccccc|}
\hline \multicolumn{1}{|c}{$\mathrm{pH}$} & 3 & 5 & 7 & & 10 \\
\hline Absorbance & 1.58 & 0. & & & \\
$\mathrm{Cu}^{2+}$ concentration & 1.46 & 0.77 & & & 0.16 \\
Removal rate & $85.4 \%$ & $92.3 \%$ & $94.9 \%$ & $96.7 \%$ & $98.4 \%$ \\
\hline
\end{tabular}

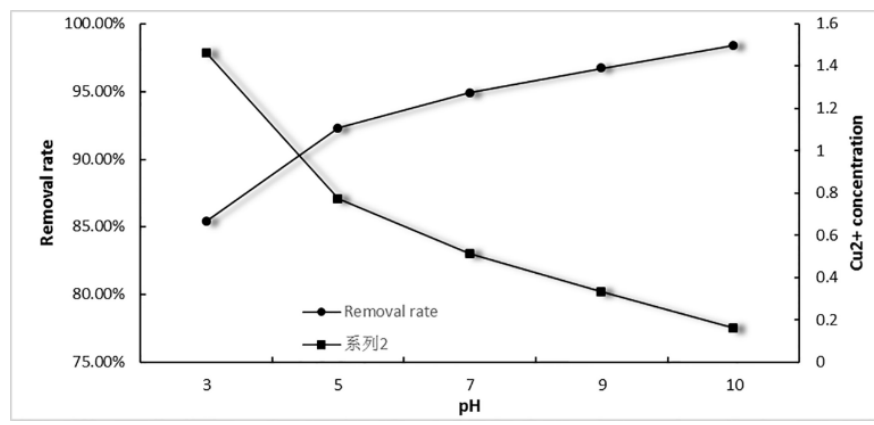

Figure 5: The Influence of Different $\mathrm{pH}$ Value on Flocculation Properties

From the above chart, we can see that the removal rate can reach nearly $95 \%$ when the wastewater $\mathrm{pH}$ is about 7 . As the $\mathrm{pH}$ value increases, the copper ion removal rate further increases. This is due to the precipitation of $\mathrm{Cu}(\mathrm{OH})_{2}$, but most of the copper ion removal rate is due to the adsorption flocculation of the corn cob xanthate.

\section{CONCLUSIONS}

Corncob preparation of cellulose xanthate as a flocculant has a good effect on the adsorption of heavy metal ions in flocculating wastewater. This paper focuses on the flocculation effect of $\mathrm{Cu}^{2+}$ ion-containing wastewater. Through the selection of different experimental conditions in the corn cob modification test, the optimal test conditions for the modification process were obtained: When the concentration of $\mathrm{NaOH}$ was $20 \%$, the swelling temperature was $20^{\circ} \mathrm{C}$, and $\mathrm{CS}_{2}$ dosage was $0.5 \mathrm{ml} / \mathrm{g}$ during the swelling process, the cornstarch xanthate had the best removal effect on $\mathrm{Cu}^{2+}$ wastewater. This paper also discussed the selection of experimental conditions for the treatment of copper-containing wastewater from corn cob xanthate, and found that the flocculation and adsorption effect was better when the flocculant dosage was $0.7 \mathrm{mg} / \mathrm{g}$ and the $\mathrm{pH}$ of the wastewater was 7-9 good.

\section{REFERENCES}

[1] Yin, H., Peng, H., Xiao, J. 1998. Development and application of modified cationic natural polymer flocculant. Industrial Water Treatment.

[2] Chen, Y. 1999. Researching and applicationof nature organic flocculant. Technigues \& Equipment for Enviro.poll.cont.

[3] Kumar, M. N.V. R. 2000. A review of chitin and chitosan applications. Reactive and Functional Polymers, 46 (1), 1-27.

[4] Chen, H. 2005. Comprehensive use of jade. Grain circulation technology.

\section{ABOUT THE AUTHORS}

Ze Li, postgraduate, research field: Environmental pollution source governance and analysis.

*Corresponding author: Wanhai,Li*, graduate supervisor, research field: Environmental pollution source governance and analysis E-mail: 2532272507@qq.com 